\title{
THE PERFORMANCE OF GREEN SYNTHESIS OF GRAPHENE OXIDE PREPARED BY MODIFIED HUMMERS METHOD WITH OXIDATION TIME VARIATION
}

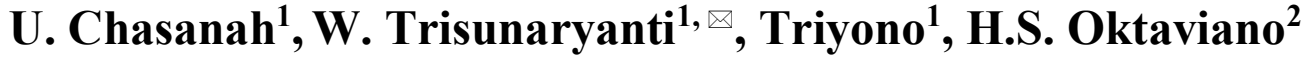 \\ and D.A Fatmawati ${ }^{1}$
}

${ }^{1}$ Department of Chemistry, Faculty of Mathematics and Natural Sciences, Universitas Gadjah Mada, Sekip Utara Bulaksumur, Sleman, D.I. Yogyakarta, 55281, Indonesia

${ }^{2}$ Research \& Technology Center, PT. Pertamina (Persero), Sopo Del Tower A, Floor 51, Jl. Mega Kuningan Barat III, Kawasan Mega Kuningan, Jakarta Selatan, DKI Jakarta, 12950, Indonesia

${ }^{\square}$ Corresponding Author: wegats@ugm.ac.id

\begin{abstract}
Attempt to reduce oxidation time is an important step toward the green chemistry approach in GO synthesis process. Graphene oxide (GO) preparation by modifying the hummer method has been studied. GO was produced by mixing potassium permanganate $\left(\mathrm{KMnO}_{4}\right)$, graphite powder, and sulfuric acid/phosphoric acid $\left(\mathrm{H}_{2} \mathrm{SO}_{4} / \mathrm{H}_{3} \mathrm{PO}_{4}\right)$ with a variation oxidation time of $6 \mathrm{~h}, 12 \mathrm{~h}$, and $18 \mathrm{~h}$. GO was characterized by UV-Visible spectroscopy, Fourier Transform InfraRed (FT-IR) spectroscopy, X-ray Diffraction (XRD), Scanning Electron Microscopy (SEM), and Transmission Electron Microscopy-Selected Area Electron Diffraction (TEM SAED). The results showed that even with $6 \mathrm{~h}$ of oxidation time. GO has been successfully formed. GO-6h has characteristics almost the same as GO $12 \mathrm{~h}$ and GO $18 \mathrm{~h}$ that indicated reducing oxidation time was a success.
\end{abstract}

Keywords: Graphene Oxide, Green Synthesis, Modified Hummer, Oxidation Time

RASĀYAN J. Chem., Vol. 14, No.3, 2021

\section{INTRODUCTION}

Graphene is a graphite monolayer that consists of carbon atom hybridization $\mathrm{sp}^{2}$ of having hexagonal structures. ${ }^{1}$ Graphite oxidation by using a strong oxidizing agent will change the structure of the graphite layer. ${ }^{2}$ Graphite oxidation introduces several oxygen functional groups attached to its plane or its basal edges, which makes hydrophilic (GO) sheets form steady aqueous or neutral colloids. ${ }^{3}$ Graphite has a similar layered structure as that of graphene oxide (GO), but the plane of carbon atoms in GO is heavily decorated by oxygen-containing groups, which not only expand the interlayer distance but also make the atomic-thick layers hydrophilic. As a result, these oxidized layers can be exfoliated under moderate ultrasonication. ${ }^{4} \mathrm{GO}$ is an oxidized chemical form of graphene. It consists of many molecular collections, for example, hydroxyl, carboxyl, and epoxy gatherings. ${ }^{5}$

$\mathrm{GO}$ can be used as precursors to make reduced graphene oxide ( $\mathrm{rGO}$ ) but $\mathrm{GO}$ itself also has extraordinary physical and chemical properties that require materials sought for other applications that are provided electronically, biomedically, energy, and environmentally ${ }^{6-8}$, as adsorbing contaminants ${ }^{9}$, and solar desalination. ${ }^{10}$

The Hummers method is often used in synthesizing GO because it is easier to do, efficient, inexpensive, and does not produce gas such as $\mathrm{NO}_{2}, \mathrm{~N}_{2} \mathrm{O}_{4}$, or $\mathrm{ClO}_{2}{ }^{3}$ Synthesize $\mathrm{GO}$ from graphite using the modified Hummers method without using $\mathrm{NaNO}_{3}$ to avoid the release of altered gases such as $\mathrm{NO}_{2}$ and $\mathrm{N}_{2} \mathrm{O}_{4}{ }^{4}$ and also residual ions $\left(\mathrm{Na}^{+}\right.$and $\left.\mathrm{NO}_{3}{ }^{-}\right)$during synthesis that will become wastewater. The modified Hummers method also produces carbon in addition to hydrophilic, better conductivity, no gas produced, and the result of GO is much better. ${ }^{11}$ Modification of the Hummers method can be carried out using different amounts of graphite, different oxidant concentrations, reaction times, and temperatures used. ${ }^{12}$ 
RASĀYAN J. Chem.

Vol. 14 | No. 3 |2017-2023| July - September | 2021

Increasing oxidation time leads to increase GO peeling and breaking. In addition, it has been studied that carboxylic groups are usually attached to the edges of graphene oxide. Therefore, more edges of graphene oxide are exposed to oxidants as oxidation time increases, thereby increasing the formation of carboxylic groups. Likewise, with the increase in oxidation time for the sample, a non-oxidized state and a relatively larger $\mathrm{sp}^{2}$ conjugate are obtained, reaching large acquisition coordination in the long-wavelength region. ${ }^{13}$ Previous experiment used an oxidation time of 12 hours to get GO. ${ }^{14}$ Therefore, this study will examine variations in oxidation time on GO formation.

\section{EXPERIMENTAL}

\section{Materials}

Hydrochloric acid $(\mathrm{HCl} 37 \%)$, sulfuric acid $\left(\mathrm{H}_{2} \mathrm{SO}_{4} 98 \%\right)$, graphite, orthophosphoric acid $\left(\mathrm{H}_{3} \mathrm{PO}_{4} 85 \%\right)$, potassium permanganate $\left(\mathrm{KMnO}_{4}\right)$, hydrogen peroxide $\left(\mathrm{H}_{2} \mathrm{O}_{2} 30 \%\right)$, silver nitrate $\left(\mathrm{AgNO}_{3}\right)$, barium chloride $\left(\mathrm{BaCl}_{2}\right)$ and ethanol were purchased from Merck, deionized water was from Aldrich sigma, while bi-distilled water and phosphate-buffered saline (PBS) is utilized

\section{General Procedure}

Graphene oxide was synthesized by the modified improved hummer method. First, $\mathrm{KMnO}_{4}$ and graphite with a ratio $(\mathrm{w} / \mathrm{w})$ of $6: 1$ were mixed. The mixture was crushed using a mortar for 5 minutes then allowed to stand at a temperature below $5{ }^{\circ} \mathrm{C}$ for 6 hours. In a different beaker glass, $\mathrm{H}_{2} \mathrm{SO}_{4}$ and $\mathrm{H}_{3} \mathrm{PO}_{4}$ acid solutions (v/v 9:1) were mixed with the same treatment. Both of the mixtures of different beaker glass were stirred for 24 hours at $65{ }^{\circ} \mathrm{C}$. After completing the stirring process, the mixtures were kept for 30 minutes at ambient temperature. The beaker was then put into solid (ice) deionized water (DI) $400-500 \mathrm{mg}$ and stirred. The solution formed was then added $7 \mathrm{~mL} \mathrm{H}_{2} \mathrm{O}_{2}$, and then a turmeric yellow color was developed. The solution was centrifuged at 8000 rotation per minute (rpm) for 5 minutes, and then it was washed using $37 \% \mathrm{HCl}(2 \mathrm{x})$, ethanol (3x), deionized water (DI) (3x). The precipitate was washed with Phosphate Buffer Saline (PBS) until pH 7. The neutral solution was checked by $\mathrm{AgNO}_{3}$ to detect the presence of $\mathrm{SO}_{4}{ }^{2-}$ ion and $\mathrm{BaCl}_{2}$ to detect the presence of $\mathrm{Cl}^{-}$ion. If the ions were still present, the solution was washed again using aquabides. When the solution was free of impurities, it was centrifuged again at 8000 rotations per minute (rpm) for 5 minutes. The precipitate formed was dried at $70{ }^{\circ} \mathrm{C}$ for 18 hours. ${ }^{15}$ That step was repeated with a variation of 6 and 12 hours of stirring time. The variation of oxidation time $6 \mathrm{~h}, 12 \mathrm{~h}$, and $18 \mathrm{~h}$ is denoted as GO $6 \mathrm{~h}, \mathrm{GO} 12 \mathrm{~h}$, and GO $18 \mathrm{~h}$, respectively.

\section{Detection Method}

The functional groups of graphene oxide were characterized by Fourier transform infrared (FTIR) with a range of $400-4000 \mathrm{~cm}^{-1}$ by a Shimadzu Prestige 21 using $\mathrm{KBr}$ pellets. The surface morphology of graphene oxide was analyzed by Scanning Electron Microscope (SEM, JEOL JSM-6510). X-ray diffraction (XRD) measurement was performed on a Bruker D2 Phaser diffractometer using the $\mathrm{Cu} \mathrm{K \alpha}$ as the irradiation $(\mathrm{k}=$ $0.15405 \mathrm{~nm}$ ) at a $2 \theta$ scan range of $10-90^{\circ}$ to detect crystal size. The morphologies and polycrystalline ring images of the prepared samples were taken using a Transmission Electron Microscope-Selected Area Electron Diffraction microscopy (JEOL JEM-1400). Peak graphene oxide was measured by UV-Vis 1800 from Shimadzu Scientific.

\section{RESULTS AND DISCUSSION}

The phase purity and crystallinity of each sample were characterized by X-Ray Diffraction (XRD). The characterization results are shown in Fig.-1. There was a change diffraction peak in graphite, GO 6h, GO $12 \mathrm{~h}$, and GO $18 \mathrm{~h}$. The peak of XRD of graphite gives a peek at $2 \theta=26.21^{\circ}$ (hkl 002) according to the pattern of JCPDS standard graphite diffraction No.75-2078. Peak obtained very sharp with high intensity which indicated that graphite has good crystallinity and no purity. ${ }^{16} \mathrm{GO} 6 \mathrm{~h}, \mathrm{GO} 12 \mathrm{~h}$, and GO $18 \mathrm{~h}$ have a sharp peak at $2 \theta=9.59 ; 10.91$; and $8.82^{\circ}$ respectively (hkl 002). The change in the diffraction peak occurs because the graphite has been successfully oxidized to GO with a peak shift from $\sim 26^{\circ}$ to $\sim 8-11^{\circ}$.

Bragg's equation using peak (002) reflection was used for calculating the distance (d) between graphene layers. The (002) reflection for evaluating the average height of stacking layers $(\mathrm{H})$ was calculated using Scherrer's equation with a constant equal to $0.9 .{ }^{17}$ Two-dimensional reflection for estimating the average diameter of stacking layers, denoted as D using Scherrer equation with Warren constant of $1.84{ }^{18}$

GREEN SYNTHESIS OF GRAPHENE OXIDE

2018 
RASĀYAN J. Chem.

Vol. 14 | No. 3 |2017-2023| July - September | 2021

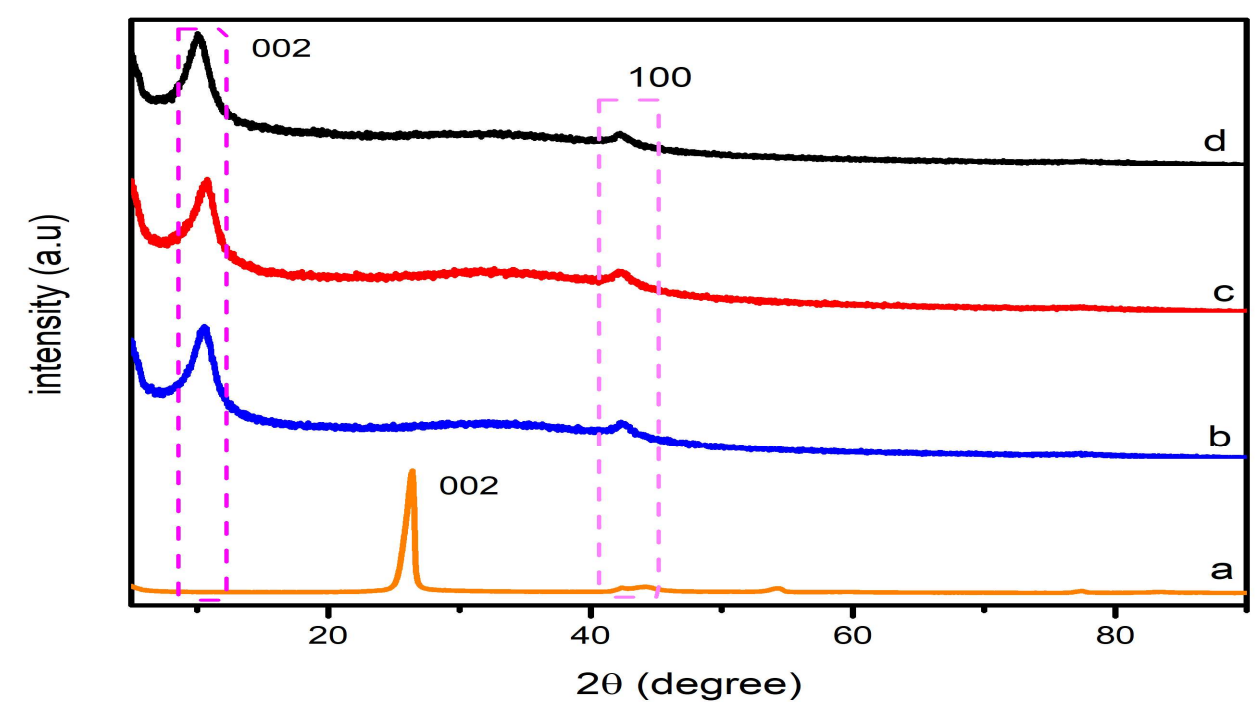

Fig.-1: Peak of X-Ray Diffraction (XRD) of (a) Graphite (b) GO 6h (c) GO 12h (d) GO 18h

Table-1: Comparison of structural parameters of GO 6h, GO 12h, and GO 18h resulting from the XRD patterns. Notation: $\mathrm{H}$ - the average height of samples GO stacking nanolayers, D- GO average diameter in stacking layers, $\mathrm{N}$ - the average number of graphene layers average number, $\mathrm{d}$ - the average distance between graphene layers.

\begin{tabular}{l|l|c|c|c|c|c|c|c}
\hline Sample & \multicolumn{7}{c}{ Peak (002) } & \multicolumn{3}{c}{ Peak (100) } \\
\hline & $2 \theta(\mathrm{deg})$ & FWHM (deg) & $\mathrm{H}(\mathrm{nm})$ & $\mathrm{d}(\mathrm{nm})$ & $\mathrm{N}$ & $2 \theta(\mathrm{deg})$ & FWHM $(\mathrm{deg})$ & $\mathrm{D}(\mathrm{nm})$ \\
\hline Graphite & 26.21 & 0.744 & 11 & 0.3 & 32 & 42.32 & 0.46 & 38 \\
\hline $6 \mathrm{~h}$ & 9.59 & 1.46 & 6 & 0.9 & $6-7$ & 42.77 & 1.11 & 15 \\
\hline $12 \mathrm{~h}$ & 10.91 & 2.75 & 3 & 0.8 & 3 & 42.80 & 1.43 & 15 \\
\hline $18 \mathrm{~h}$ & 8.82 & 1.93 & 4 & 1.0 & 4 & 42.98 & 1.18 & 15 \\
\hline
\end{tabular}

The GO $6 \mathrm{~h}$ consists of 6-7 graphene layer in a stacking nanostructure of an average diameter by the height of about $15 \mathrm{~nm} \times 6 \mathrm{~nm}$ and graphene layer distance of $0.9 \mathrm{~nm}$; GO $12 \mathrm{~h}$ has 3 graphene layers with a diameter $15 \mathrm{~nm} \times 3 \mathrm{~nm}$, whereas the graphene layer of GO $18 \mathrm{~h}$ is 4 with $15 \mathrm{~nm} \times 4 \mathrm{~nm}$ in diameter. GO usually has a distance between layers (d) that is equal to $0.6-1.0 \mathrm{~nm}^{19}$ whereas graphite has the distance between layers $0.3 \mathrm{~nm}$ The increase of distance between layers (d) from graphite to GO indicating graphite oxidation after a chemical reaction has been successfully formed.

Evaluation of functional groups of graphite and as-synthesized GO was done by Fourier Transform Infrared (FTIR). The formation $\mathrm{C}-\mathrm{O}, \mathrm{C}-\mathrm{OH}$ and $\mathrm{C}=\mathrm{C}$ functional groups indicate exfoliation graphite becomes GO. The oxidation process causes the formation of $\mathrm{C}-\mathrm{O}$ groups from epoxy groups in the $\mathrm{GO}$ structure, and $\mathrm{C}=\mathrm{O}$ groups are formed due to chain oxidation carbon produces ketone or carbonyl groups. ${ }^{21}$ Figure-2 shows that graphite does not have a significant peak except $\mathrm{O}-\mathrm{H}$ functional group. ${ }^{22}$ Fig. -2 indicates occurring oxidation graphite to $\mathrm{GO} .{ }^{23}$ The absorption peak of $\mathrm{O}-\mathrm{H}, \mathrm{C}=\mathrm{C}, \mathrm{C}-\mathrm{O}$, and $\mathrm{C}-\mathrm{O}$ functional group formed can be seen in Table- 2 .

Table-2: The Absorption Peak of Graphite, GO 6h, GO 12h, and GO 18h

\begin{tabular}{c|c|c|c|c}
\hline \multirow{2}{*}{ Sample } & \multicolumn{4}{|c}{ Functional Group } \\
\cline { 2 - 5 } & $\mathrm{O}-\mathrm{H}\left(\mathrm{cm}^{-1}\right)$ & $\mathrm{C}=\mathrm{C}\left(\mathrm{cm}^{-1}\right)$ & $\mathrm{C}-\mathrm{OH}\left(\mathrm{cm}^{-1}\right)$ & $\mathrm{C}-\mathrm{O}\left(\mathrm{cm}^{-1}\right)$ \\
\hline Graphite & 3422 & & & \\
\hline GO 6 h & 3413 & 1603 & 1352 & 1038 \\
\hline GO 12 h & 3424 & 1613 & 1354 & 1027 \\
\hline GO 18 h & 3429 & 1623 & 1355 & 1017 \\
\hline
\end{tabular}


RASĀYAN J. Chem.

Vol. 14 | No. 3 |2017-2023| July - September | 2021

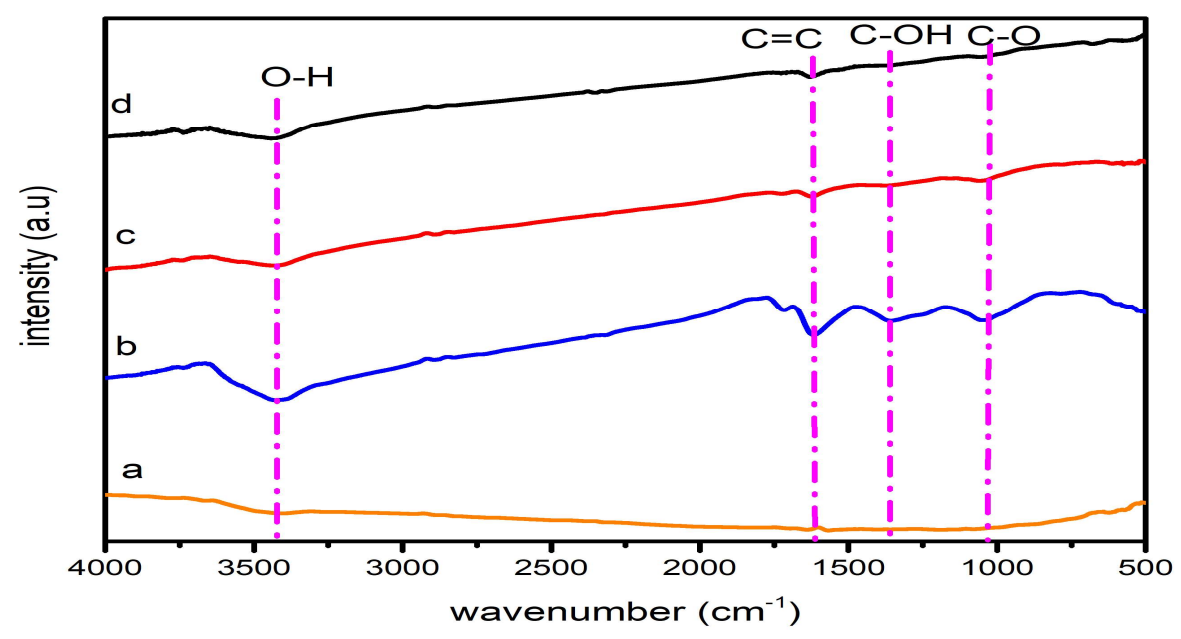

Fig.-2: FTIR Spectra of (a) graphite (b) GO 6h, (c) GO 12h, and (d) GO 18h

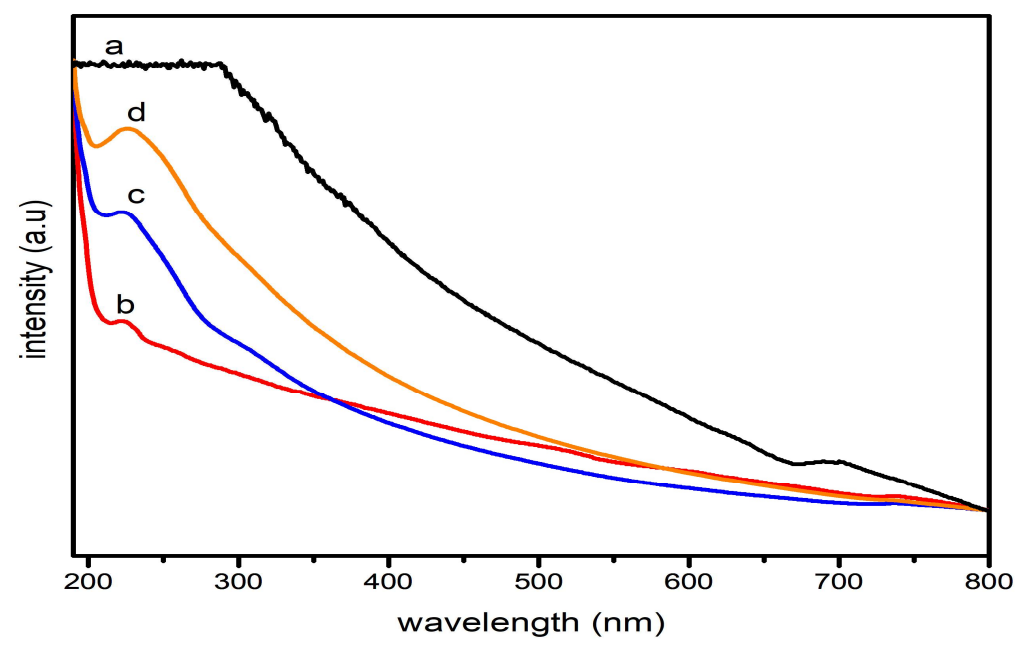

Fig.-3: UV-Visible Spectra recorded in (a) Graphite, (b) GO 6h, (c) GO 12h, and (d) GO 18h

The effect of these parameters on the oxidation time of graphene oxide was studied using UV-Visible spectra, Fig.-3(a). The absorption peak was at $225 \mathrm{~nm}$ for GO 6h, $226 \mathrm{~nm}$ for GO 12h, and $228 \mathrm{~nm}$ for GO $18 \mathrm{~h}$. Transitions of $\mathrm{C}=\mathrm{C}$ aromatic from $\mathrm{sp}^{2}$ bonding correspond to $\pi \rightarrow \pi^{*}$. The more conjugation of $\pi \rightarrow \pi^{*}$ transitions affects decreasing energy needed for the electronic transition, which results in a higher $\lambda$ max. The $\mathrm{n} \rightarrow \pi^{*}$ transition of the carbonyl groups $(\mathrm{C}=\mathrm{O})$ was also observed around $300 \mathrm{~nm}$ for all three samples, similar to literature. ${ }^{24}$ The absorption peak for sample GO $6 \mathrm{~h}$ is the lowest wavelength $(225 \mathrm{~nm})$ compared to others. The delocalized electrons might decrease, and it was claimed that higher energy was required for the electronic transition as compared with GO $12 \mathrm{~h}$ and GO $18 \mathrm{~h}$. This indicated that the sample was more oxidized with more functional groups on the basal planes. A shift of $\pi \rightarrow \pi^{*}$ towards a higher wavelength or a region of visible light, signaling the growth of $\mathrm{sp}^{2}$ graphene sheets. ${ }^{25}$ This redshift in UV Vis absorption is due to the hybridization $\mathrm{sp}^{2}$ carbon atoms and an increase in the number of electrons. The peak intensity of GO increased with the increasing reaction time of GO $6 \mathrm{~h}(0.66), \mathrm{GO} 12 \mathrm{~h}(0.9)$, and GO $18 \mathrm{~h}(1.59)$. This suggests that enough time is required for a higher degree of oxidation. ${ }^{26}$ The UV Vis spectra of carbon materials show $\pi \rightarrow \pi^{*}$ transition peak in the $200 \mathrm{~nm}$ area due to the presence of $\mathrm{sp}^{2}$ hybridization of carbon atoms indicating that reducing oxidation time of GO $6 \mathrm{~h}$ has $\mathrm{sp}^{2}$ peak transition. 
RASĀYAN J. Chem.

Vol. 14 | No. 3 |2017-2023| July - September | 2021
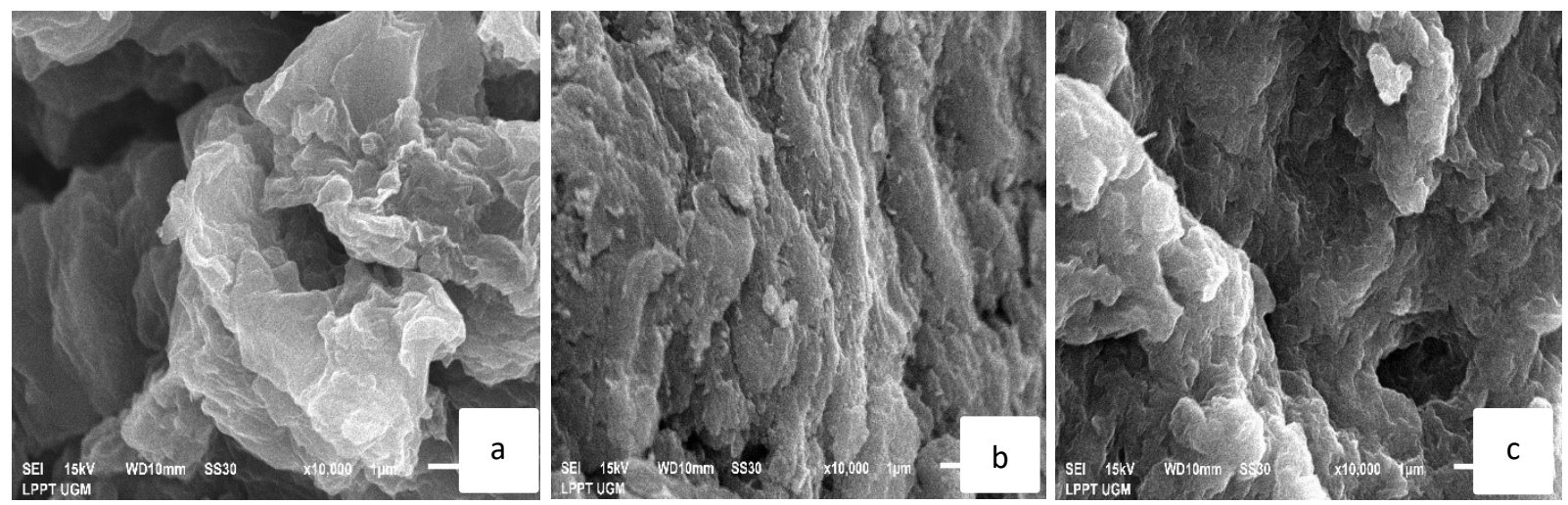

Fig.-4: SEM images of (a) GO 6h, (b) GO 12h, and (c) GO 18h

Morphological of GO in three variations can be seen in Fig.-4. Variation oxidation times of GO 6h, GO $12 \mathrm{~h}$, and GO $18 \mathrm{~h}$ don't affect the morphology result. Morphology of all variations of GO revealed thick flat flake layers, rough surface, not crumpled and irregular shape. The disordered and unwrinkled structure was owing to the unremoval of oxygen atoms and a high degree of exfoliation during the oxidation process. ${ }^{27}$ Moreover, irregular shapes and unorganized were caused by cracking of structure that occurred during the oxidation process.
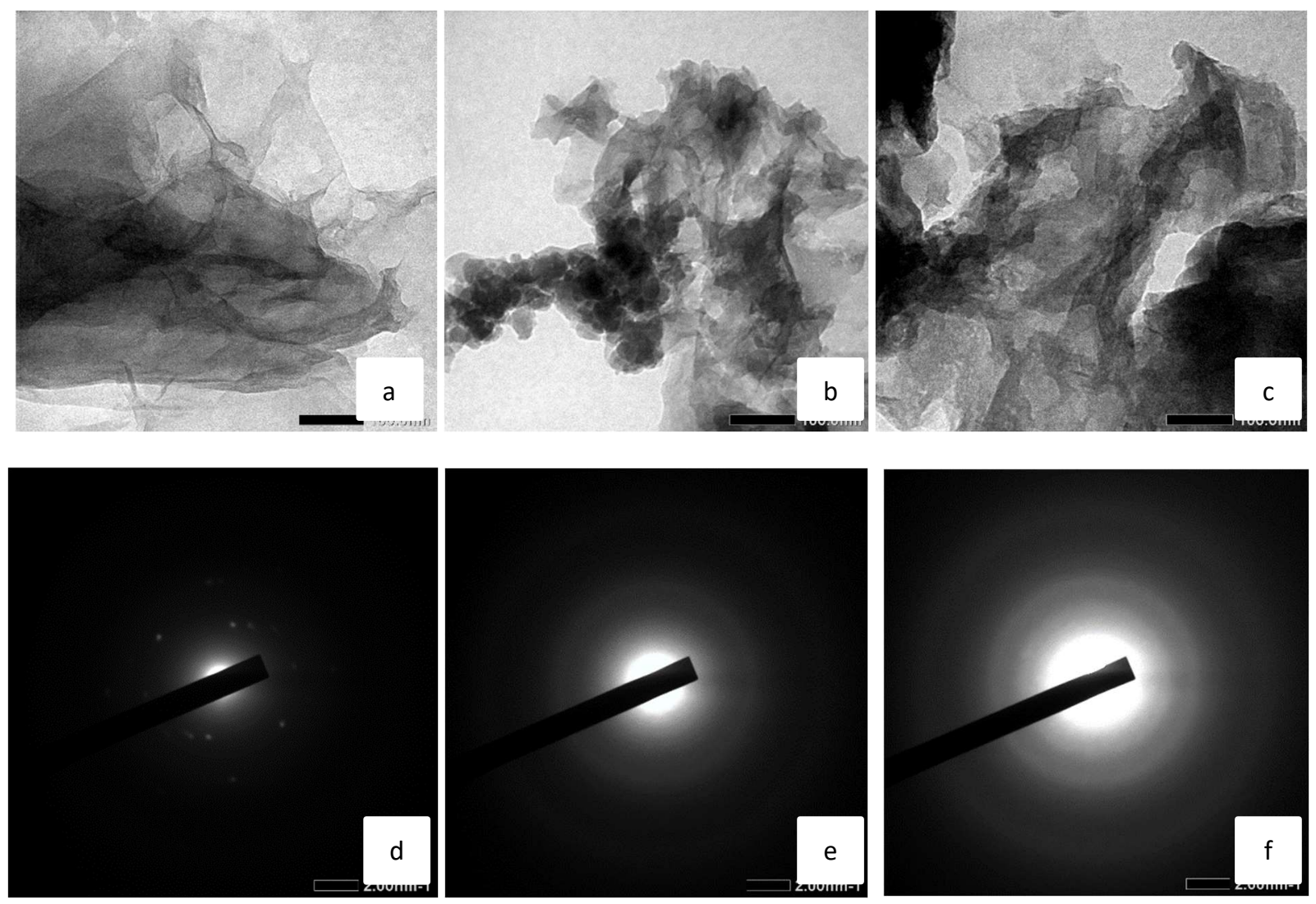

Fig.-5: TEM images of (a) GO 6h, (b) GO 12h, and (c) GO 18h and SAED images of (d) GO 6h, (e) GO 12h, and (f) GO $18 \mathrm{~h}$

Dark areas (Fig.-5a, b, c) indicate the thick stacking nanostructure of several graphene oxides and/or graphene layers with some amount of oxygen functional groups. All GO samples emerged as semitransparent which describes the material is not stable under high energy beam. ${ }^{27}$ Dark areas indicate the thick stacking nanostructure of several graphene oxide layers with some amount of oxygen functional groups. The higher transparency areas were resulted from stacking nanostructure exfoliation. ${ }^{17}$ From Fig.- 
RASĀYAN J. Chem.

Vol. 14 | No. 3 |2017-2023| July - September | 2021

$5 \mathrm{~d}$, it can be seen that $\mathrm{GO}$ at $6 \mathrm{~h}$ begins to form polycrystalline, but it is still predominantly amorphous, then in Fig.-5e and 5f, GO 12h and GO 18h have polycrystalline form.

Table-3: Calculation d spacing of Three Variations of GO 6h, GO 12h, and GO $18 \mathrm{~h}$

\begin{tabular}{c|c|c}
\hline Sample & $\mathrm{R}(1 / \mathrm{nm})$ & $\mathrm{d}(\mathrm{nm})$ \\
\hline GO 6 h & 1.15 & 0.9 \\
\hline GO 12 h & 1.28 & 0.8 \\
\hline GO 18 h & 1.04 & 1 \\
\hline
\end{tabular}

From Table-3, the results of the calculation of SAED pattern have $d$ values that are similar to the calculation of $d$ spacing of XRD GO. The result $d$ is in the range of the distance between the graphene oxide layers between 0.6-1.0 nm. ${ }^{20}$ Increasing d-spacing from graphite (Table-1) to GO indicated oxidation occurs causes the introduction of oxygen functional groups entering among the graphene layer which can be proven by FTIR characterization. ${ }^{20}$

\section{CONCLUSION}

Green synthesis of graphene oxide (GO) with oxidation time variation has been successfully studied. Spectra of X-Ray Diffraction (XRD) of GO 6h, 12h, and $18 \mathrm{~h}$ appeared to have a sharp peak at $2 \theta=\sim 10^{\circ}$, calculation of d spacing GO $6 \mathrm{~h}, 12 \mathrm{~h}$, and $18 \mathrm{~h}$ are respectively $0,9 \mathrm{~nm}, 0.8 \mathrm{~nm}$, and $1.0 \mathrm{~nm}$. Peaks of UVVis indicate all of the samples GO formed at $225 \mathrm{~nm}$ of GO 6h, $226 \mathrm{~nm}$ of GO 12h, and $228 \mathrm{~nm}$ of GO $18 \mathrm{~h}$. These peaks are corresponding to $\pi \rightarrow \pi^{*}$ transitions for the $\mathrm{C}=\mathrm{C}$ aromatic from $\mathrm{sp}^{2}$ bonding. According to FTIR analysis, among all the samples are formed functional groups indicating GO. The Scanning Electron Microscopy (SEM) images show the layered and irregularly shaped. Selected Area Diffraction (SAED) of Transmission Electron Microscopy (TEM) all of the samples resulted in the same d spacing with XRD calculation. GO $6 \mathrm{~h}$ has characteristics almost the same as GO $12 \mathrm{~h}$ and GO $18 \mathrm{~h}$ that indicated reducing oxidation time was a success.

\section{ACKNOWLEDGMENT}

The authors thank the Indonesian Ministry of Technology Research and Higher Education, The Republic of Indonesia, for the financial support under the scheme of PMDSU research grant 2019 (Contract number: 6319/UN1/DITLIT/DIT-LIT/LT/2019).

\section{REFERENCES}

1. H. Yu, B. Zhang, C. Bulin, R. Li, R. Xing. Scientific Reports, 6, 1(2016), http://doi.org/10.1038/srep36143

2. D. Ratih, R. Siburian, Andriayani, Rasayan Journal of Chemistry, 11(4), 1649(2018), http://doi.org/10.31788/RJC.2018.1145007

3. P. Divya, A. Prithiba and R. Rajalakshmi, Rasayan Journal of Chemistry. 12(1), 214(2019), http://doi.org/10.31788/RJC.2019.1215039

4. S.N. Alam, N. Sharma, L. Kumar, Graphene, 6, 1(2017), http://doi.org/10.4236/graphene.2017.61001

5. J. Pachiyappan and N. Gnanasundaram, Rasayan Journal of Chemistry,13(3), 2027(2020), http://doi.org/10.31788/RJC.2020.1335827

6. O. Akhavan, E. Ghaderi, S.A. Shirazian, and R. Rahighi, Carbon, 97, 71(2016), http://doi.org/10.1016/j.carbon.2015.06.079

7. X. Li, Proceedings of the National Academy of Sciences, 113(49), 13953(2016), http://doi.org/10.1073/pnas.1613031113

8. P, Poulin, R. Jalili, W. Neri, F. Nallet, T.T. Divoux, T., A. Colin, S. A. Seyed Hamed Aboutalebi, G. G. Wallace, C.C. Zakri, Proceedings of the National Academy of Sciences, 113(40), 11088(2016), http://doi.org/10.1073/pnas.1605121113

9. J. Bong, K. Taekyung, K. Seo, C. Kwon, J.H. Park, S.K. Kwak, and S. Ju, Scientific Reports, 5, 14321 (2015). http://doi.org/10.1038/srep14321

10. Y.T. Li, J.M. Xu, Z.J. Tang, T.T. Xu, X.J. Li, Journal of Alloys and Compounds, 715, 122(2017), http://doi.org/10.1016/j.jallcom.2017.04.286

11. M.S. Chang, Y.S. Kim, J.H. Kang, J. Park, S.J. Sung, S.H. So, K.T. Park, S.J. Yang, T. Kim, and C.R. Park, Chemistry of Materials, 29, 307(2017), http://doi.org/10.1021/acs.chemmater.6b02885 
RASĀYAN J. Chem.

Vol. 14 | No. 3 |2017-2023| July - September | 2021

12. J. Park, Y.S. Cho, S.J. Sung, M. Byeon, S.J. Yang, C.R. Park, Energy Storage Mater, 14, 8(2018), http://doi.org/10.1016/j.ensm.2018.02.013

13. QD. Yang, Journal of Materials Chemistry, 5, 9852(2017), http://doi.org/10.1039/C7TA01752A

14. R. Tarcan, M. Handrea-Dragan, O. Todor-Boer, I. Petrovai, C. Farcau, M. Rusu, A. Vulpoi, M. Todea, S. Astilean, I. Botiz, Synthetic Metals, 269, 116576(2020), http://doi.org/10.1016/j.synthmet.2020.116576

15. P. Ranjan, S. Agrawal, A. Sinha, R. Rao, J. Balakrishnan and A.D. Thakur, Nature, 8,12007(2018), http://doi.org/10.1038/s41598-018-30613-4

16. X.B. Hu, Y. Yu, J.E. Zhou, L.X. Song, Advanced Materials Research, 750-752, 1113(2013), http://doi.org/10.4028/www.scientific.net/AMR.750-752.1113

17. L. Stobinski, B. Lesiak, A. Malolepszy, M. Mazurkiewicz, B. Mierzwa, J. Zemek, P. Jiricek and I. Bieloshapka, Journal of Electron Spectroscopy and Related Phenomena, 195, 145(2014), http://doi.org/10.1016/j.elspec.2014.07.003

18. B.E. Warren, Physical Review, 59, 693(1941), http://doi.org/10.1103/PhysRev.59.693

19. P. Ramesh, S. Bhagyalakshmi, and S. Sampath, Journal of Colloid and Interface Science, 274, 1, 95(2004), http://doi.org/10.1016/j.jcis.2003.11.030

20. K.Prabakaran, P.J.Jandas, S. Mohantya and S.K. Nayak,Solar Energy, 170, 442(2018), http://doi.org/10.1016/j.solener.2018.05.008

21. D. Khalili, New Journal of Chemistry, 40, 2547(2016), http://doi.org/10.1039/C5NJ02314A

22. M. Bera, P. Gupta, and P.K Maji, Journal of Nanoscience and Nanotechnology, 18, 902(2018), http://doi.org/10.1166/jnn.2018.14306

23. A. Hussein, S. Sarkar, and B. Kim. Journal of Materials Science \& Technology, 32(5), 411(2016), http://doi.org/10.1016/j.jmst.2016.02.001

24. T.F. Emiru and DW Ayele, Egyptian Journal of Basic and Applied Sciences, 4, 74(2017), http://doi.org/10.1016/j.ejbas.2016.11.002

25. H. Ding' S. Zhang, J. Chen, X.P Hud, Z. F, Du, Y.Qiua and D.L. Zhao, Thin Solid Films, 584, 29(2015), http://doi.org/10.1016/j.tsf.2015.02.038

26. D. C. Marcano, D.V, Kosynkin, J.M. Berlin, A. Sinitskii, Z. Sun, A. Slesarev, L.B. Alemany, W. Lu, and JM Tour, ACS Nano, 4(8), 4806(2010), http://doi.org/10.1021/nn1006368

27. A. K Mishra and S. Ramaprabhu, Journal of Physical Chemistry C, 115(29), 14006(2011), http://doi.org/10.1021/jp201673e

[RJC-6042/2020] 